\title{
Tethering Small Molecules to a Phage Display Library: Discovery of a Selective Bivalent Inhibitor of Protein Kinase A
}

\section{Supporting Information}

Scott C. Meyer, Carolyn D. Shomin, Thomas Gaj, and Indraneel Ghosh

Department of Chemistry, University of Arizona, Tucson, Arizona 85721

Contents:

S1. General Materials

S2. Design and Synthesis of JunAdoC and JunStaur

S2.1. Synthesis of AdoC, 6, and Carboxylated Staurosporine, 2

S2.2. Synthesis of Jun conjugates via solid phase peptide synthesis

S3. Validation of the Phage Displayed Fos Conjugated Cyclic Peptide Library

S3.1. LinkJun synthesis

S3.2. Phage competition assay

S4. Active Site Directed In Vitro Selection Against PKA

S4.1. Biotinylation of PKA

S4.2. Active site directed phage displayed peptide selection against PKA

S5. Evaluation of Selected Cyclic Peptides

S5.1. Synthesis of Selected Cyclic Peptides

S5.2. PKA Inhibition Assay

S5.3. Synthesis of cyclo(CTFRVFGC)G Staurosporine Conjugate, 4

S5.4. PKA Inhibition by the Carboxylated Staurosporine Derivative 2, Cyclic Peptide 3, and Bivalent Inhibitor 4

S5.5. Millipore Kinase Profiler Screen

S6. Structural Alignment of Kinases 


\section{S1. General Materials}

M13KO7 Helper phage and cloning enzymes were purchased from New England Biolabs; peptide synthesis reagents and resin were purchased from Novabiochem; staurosporine was purchased from LC Laboratories (Woburn, MA); PKA was obtained from Promega; DNA primers were obtained from IDT (Integrated DNA Technologies); all other reagents, unless otherwise noted, were purchased from Sigma.

\section{S2. Design and Synthesis of JunAdoC and JunStaur}

We chose the Fos-Jun coiled coil heterodimerization domain to non-covalently tether the active site directing small molecule to the phage displayed cyclic peptide library (Table S1). Fos and Jun comprise a well characterized parallel coiled coil dimer ${ }^{\mathrm{S} 1}$ with a dissociation constant in the low nanomolar range. ${ }^{\mathrm{S}, 3,4}$ The non-covalent interaction utilized in our system provides a dynamic library that can potentially equilibrate to promote the isolation of the most thermodynamically favorable peptide/small-molecule pairs. ${ }^{\mathrm{S} 5}$ We chose to attach the peptide libraries to Fos, which has a low affinity for forming homodimers in order to prevent the cysteine containing cyclic peptide library from undergoing disulfide exchange if in close proximity. This necessitated the conjugation of our ATP competitive small molecules to Jun to provide the active site directing warhead (See Figure 1, Main Manuscript).

Table S1. Amino acid sequences

\begin{tabular}{|c|c|}
\hline Name & Sequence \\
\hline Fos & LTDTLQAETDQLEDEKSALQTEIANLLKEKEKLEFILA \\
\hline Jun & RIARLEEKVKTLKAQNSELASTANMLREQVAQLKQKVA \\
\hline Library & $C(\mathrm{X}){ }_{6} \mathrm{C}-\mathrm{GGGGAAALTDTLQAETDQLEDEKSALQTEIANLLKEKEKLEFILA-Phage}$ \\
\hline JunAdoC & (2) - $\beta A G G-R I A R L E E K V K T L K A Q N S E L A S T A N M L R E Q V A Q L K Q K V A$ \\
\hline JunStaur & (4) - $\beta A G G-R I A R L E E K V K T L K A Q N S E L A S T A N M L R E Q V A Q L K Q K V A$ \\
\hline HTB1 & TFKLIINGKTLKGEITIEAVDAAEAEKIFKQYANDNGIDGEWTYDDATKTFTVTE-Phage \\
\hline LinkJun $^{\mathrm{a}}$ & C-(PEO) ${ }_{2}$-RIARLEEKVKTLKAQNSELASTANMLREQVAQLKQKVA \\
\hline
\end{tabular}

${ }^{a}$ Contains two ethylene oxide linker residues (Novabiochem, product \#01-63-0141)

Promiscuity of the active site directing small molecule is a key feature of our design because it facilitates the generalization of this methodology to other kinases. A carboxylated 
analog of adenosine (AdoC, 6) was chosen as a promiscuous low affinity active site directing ligand. Loog, et al have previously utilized this moiety in a designed bisubstrate approach against PKA, ${ }^{\mathrm{S} 6}$ where the unfunctionalized adenosine was shown to inhibit several kinases with 100-300 $\mu \mathrm{M} \mathrm{IC}$ I0 $_{50}$ values. Furthermore, adenosine was attractive because its weak binding mimics the conditions often used in fragment-based ligand discovery, where the initial "hit" often has low affinity for the target. ${ }^{\mathrm{S} 7}$ The second active site directing small molecule, staurosporine, was chosen because it is known to be a promiscuous, high affinity inhibitor of many protein kinases. ${ }^{\mathrm{S} 8}$ The higher affinity of this inhibitor provided an opportunity to modulate the active site directing pressure applied to the selection system.

Staurosporine, $\mathbf{1}$, has been modified in the past with various functional groups at the methyl amino position. ${ }^{\text {S9 }}$ The desired carboxylated modification, 2 , reduces the affinity of staurosporine for PKA by $\sim 50$ fold to the mid nanomolar range, likely due to the loss of one or more hydrogen bonds, as seen in the crystal structure of PKA in complex with staurosporine. ${ }^{\text {S10,11 }}$ Moreover, Schepartz and coworkers have recently utilized a staurosporinelike natural product, K252a, with a chemical modification at a similar position for the bivalent inhibition of PKA. ${ }^{\text {S12 }}$ Thus 6 and $\mathbf{2}$ would potentially provide us with targeting warheads whose affinities span three orders of magnitude $(\sim 150 \mathrm{nM}-\sim 150 \mu \mathrm{M})$. The adenosine derivative (AdoC, 6) was obtained by oxidation of protected adenosine (Scheme S1) under known conditions. $^{\mathrm{S} 13}$ In the case of staurosporine, the secondary amine was acylated with succinic anhydride to provide 2 (Scheme S1). Both of the carboxyl-containing compounds were coupled
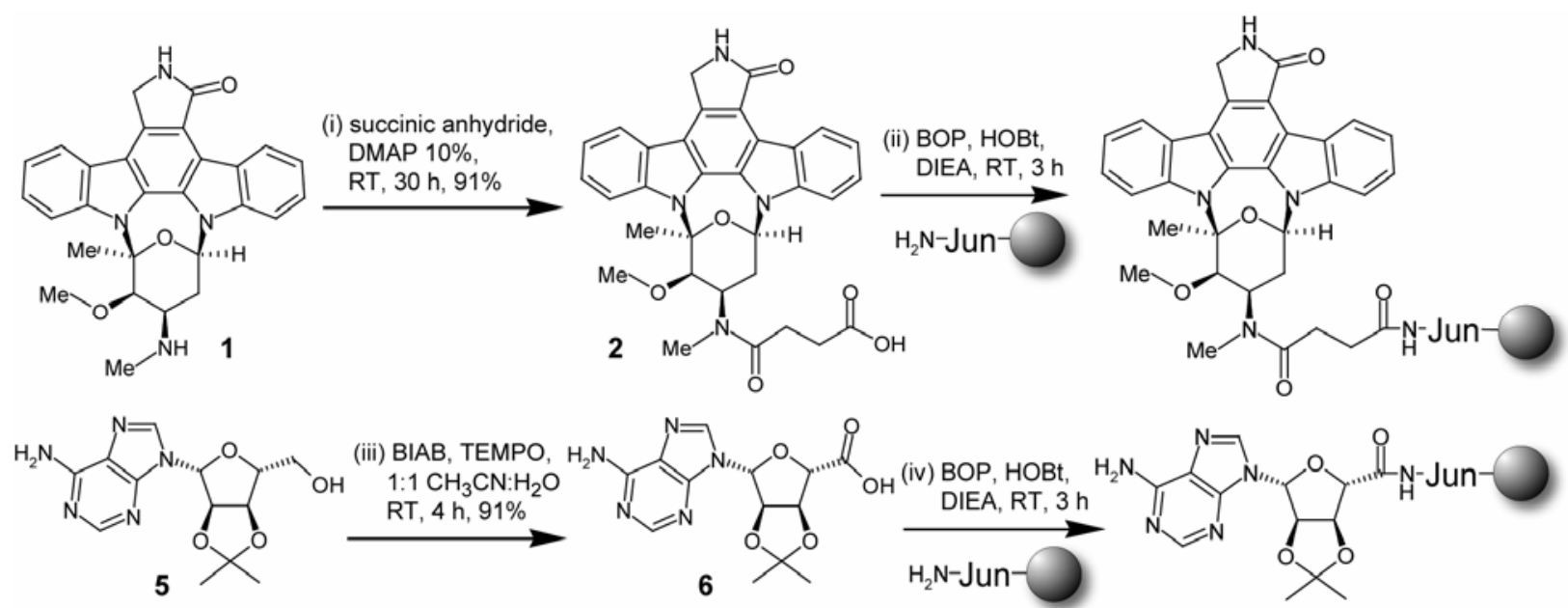

Scheme S1. Synthesis of Jun-conjugated small molecules. 
to the $\mathrm{N}$ - terminus of synthesized Jun, via a short linker, to produce JunAdoC and JunStaur, respectively (Table S1). After coupling the small molecules to synthesized Jun, the conjugates were cleaved from the solid phase synthesis resin and globally deprotected. We verified that both small molecules retained affinity for PKA when conjugated to Jun, with JunAdoC having an $\mathrm{IC}_{50}$ of $21 \pm 2 \mu \mathrm{M}$ and JunStaur with an $\mathrm{IC}_{50}$ of $78 \pm 11 \mathrm{nM}$ (Figure S2) thus providing our necessary small molecule tethers (See section S5.2. below for details).

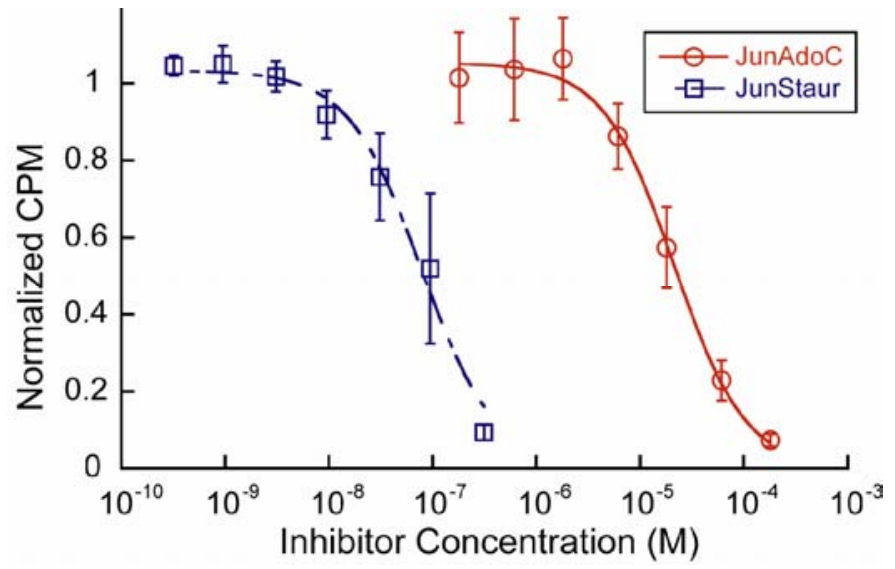

Figure S2. Inhibition of PKA with the Jun constructs JunAdoC and JunStaur. Kinase activity (normalized) of PKA was interrogated with $\left[\gamma_{-}{ }^{32} \mathrm{P}\right] \mathrm{ATP}$ and the Kemptide substrate in the presence of varying concentrations of Junconjugated small molecules. Lines indicate the calculated best fit equation for the determination of the $\mathrm{IC}_{50}$ values. Each data point is the average of at least two experiments and the error bars indicate the standard deviation.

\section{Methods}

\section{S2.1. Synthesis of AdoC, 6, and Carboxylated Staurosporine, 2}

AdoC, 6, was synthesized as described by Epp and Widlanski ${ }^{\mathrm{S} 13}$ and characterized by ${ }^{1} \mathrm{H}$ NMR and mass spectrometry (see below). For the synthesis of the previously reported staurosporine derivative $2,{ }^{\mathrm{S} 9}$ staurosporine $(24 \mu \mathrm{mol})$ was added to succinic anhydride (36 $\mu \mathrm{mol}$, 1.5 molar equivalents) and DMAP $(1.2 \mu \mathrm{mol}, 5 \mathrm{~mol} \%)$ in $1 \mathrm{~mL} \mathrm{DMSO}$, and the reaction was protected from light, at room temperature. The progress of the reaction was monitored by TLC (91.6\% chloroform, 8\% methanol, 0.4\% ammonium hydroxide). After 30 hours, staurosporine was no longer detectable in the reaction mixture. The product was precipitated in $45 \mathrm{~mL}$ of $0.1 \%$ TFA in water, isolated by centrifugation, and further purified by trituration in $0.1 \%$ TFA. The product 2 was dried under high vacuum and characterized by ${ }^{1} \mathrm{H}$ NMR and mass spectrometry (AdoC 6: expected $321.3 \mathrm{~g} / \mathrm{mol}$, found: $322.1 \mathrm{~m} / \mathrm{z}$; Carboxylated Staurosporine 2: expected $566.2 \mathrm{~g} / \mathrm{mol}$, found $566.22 \mathrm{~m} / \mathrm{z}$ ). 
${ }^{1} \mathrm{H}$ NMR of AdoC [6]: (600 MHz, DMSO-d $)_{6} \delta 8.32(\mathrm{~s}, 1 \mathrm{H}), 8.07$ (s, 1H), $7.26(\mathrm{~s}, 2 \mathrm{H}), 6.32$ (s, $1 \mathrm{H}), 5.46(\mathrm{~d}, \mathrm{~J}=6.0 \mathrm{~Hz}, 1 \mathrm{H}), 5.53(\mathrm{dd}, \mathrm{J}=1.8 \mathrm{~Hz}, \mathrm{~J}=6.0 \mathrm{~Hz}, 1 \mathrm{H}), 4.68(\mathrm{~d}, \mathrm{~J}=1.8,1 \mathrm{H}), 1.51(\mathrm{~s}$, $3 \mathrm{H}), 1.34(\mathrm{~s}, 3 \mathrm{H})$

${ }^{1} \mathrm{H}$ NMR of Carboxylated Staurosporine [2]: (600 MHz, DMSO-d $\left.\mathrm{d}_{6}\right) \delta 9.27(\mathrm{~d}, \mathrm{~J}=7.8 \mathrm{~Hz}, 1 \mathrm{H})$, $8.58(\mathrm{~s}, 1 \mathrm{H}), 8.04$ (d, J = 8.3 Hz, 1H), $7.98(\mathrm{~d}, \mathrm{~J}=8.3 \mathrm{~Hz}, 1 \mathrm{H}), 7.66$ (d, J = 8.3 Hz, 1H), 7.47 (t, J $=7.8 \mathrm{~Hz}, 2 \mathrm{H}), 7.35(\mathrm{t}, \mathrm{J}=7.6 \mathrm{~Hz}, 1 \mathrm{H}), 7.29(\mathrm{t}, \mathrm{J}=7.3 \mathrm{~Hz}, 1 \mathrm{H}), 7.03$ (t, J = 7.6 Hz, 1H), 4.99 (s, 3H), $4.21(\mathrm{~s}, 1 \mathrm{H}), 2.81(\mathrm{~s}, 3 \mathrm{H}), 2.76(\mathrm{~s}, 3 \mathrm{H}), 2.67(\mathrm{~d}, \mathrm{~J}=11.9 \mathrm{~Hz}, 1 \mathrm{H}), 2.57(\mathrm{~m}, 2 \mathrm{H}), 2.33$ (s, $3 \mathrm{H}), 2.22\left(\mathrm{dt}, \mathrm{J}_{\mathrm{d}}=6.7 \mathrm{~Hz}, \mathrm{~J}_{\mathrm{t}}=13 \mathrm{~Hz}, 1 \mathrm{H}\right)$

\section{S2.2. Synthesis of Jun conjugates via solid phase peptide synthesis}

Jun (Table S1) was synthesized using standard Fmoc protection strategies for solid phase peptide synthesis. Rink Amide AM resin $(0.43 \mathrm{mmol} / \mathrm{g})$ was used as the solid phase matrix with BOP (3 equivalents), HOBt ( 3 equivalents), and DIEA (6 equivalents) as the coupling reagents with the appropriate Fmoc protected amino acid residue (3 equivalents).

Synthesis of JunAdoC and JunStaur (Table S1) were carried out by attaching a linker of two glycine residues and one $\beta$-alanine on the N-terminus of Jun. With separate aliquots of resin, the $\beta$-alanine was coupled to the adenosine derivative $\mathbf{6}$ or the staurosporine derivative 2 under conditions identical to those used for previous amino acids. Cleavage of each peptide was carried out with 94\% TFA, 2.5\% EDT, $2.5 \%$ water, and 1\% TIPS for 2 hours. The peptides were precipitated by the addition of chilled diethyl ether, isolated by centrifugation, and triturated with more chilled ether. HPLC purification (JunAdoC: 10\% to 60\% and JunStaur: $25 \%$ to $65 \%$ acetonitrile gradient in water with $0.1 \%$ TFA) afforded the pure peptides which were characterized by mass spectrometry (JunAdoC: expected $4742 \mathrm{~g} / \mathrm{mol}$, found $4742.4 \mathrm{~m} / \mathrm{z}$; JunStaur: expected $5027 \mathrm{~g} / \mathrm{mol}$, found $5029.2 \mathrm{~m} / \mathrm{z}$ ) 

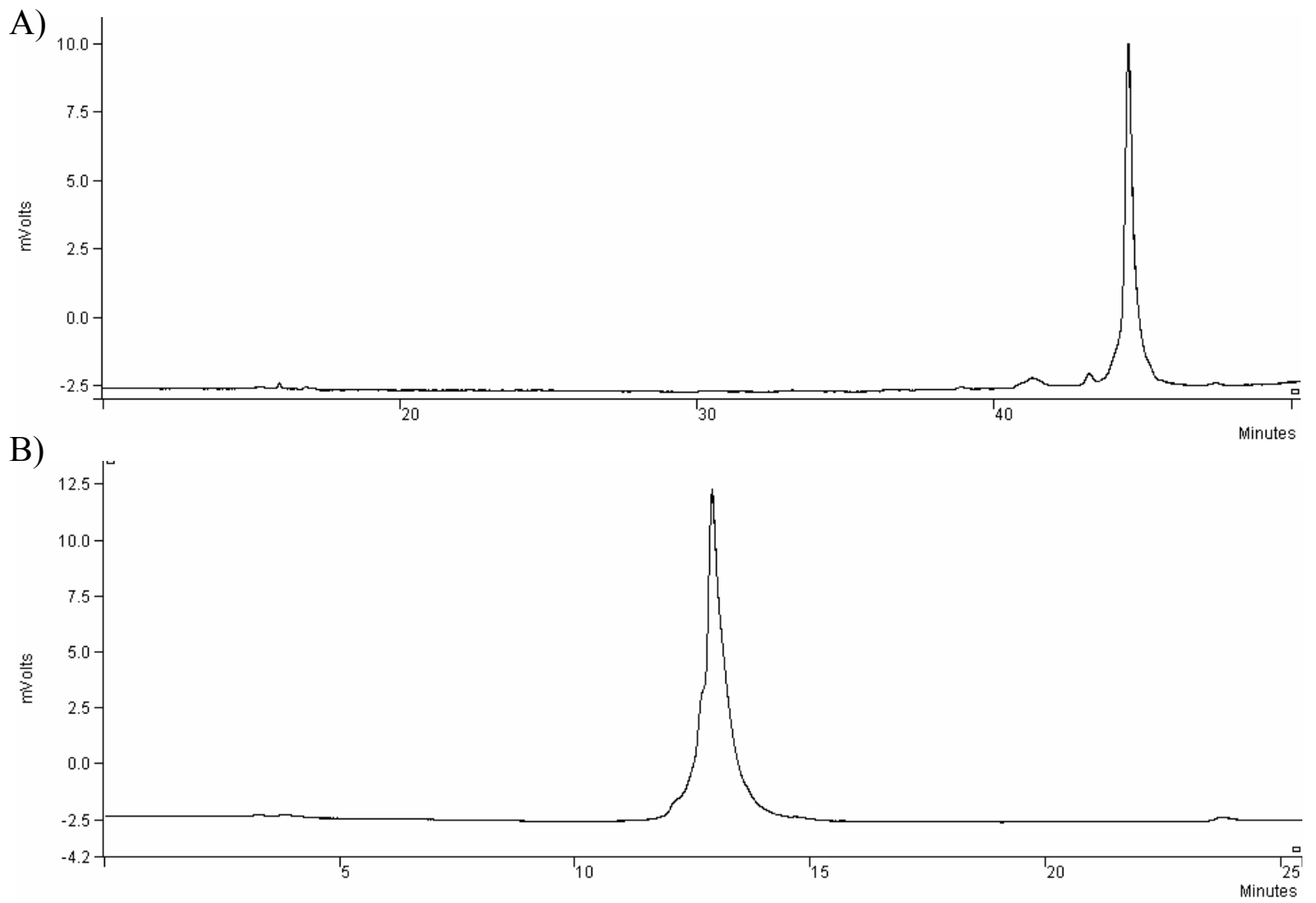

Figure S3: HPLC traces of the A) AdoC-Jun and B) staurosporine-Jun conjugates

\section{S3. Validation of the Phage Displayed Fos Conjugated Cyclic Peptide Library}

To complete the other half of our small-molecule directed selection system, a 6 residue cyclic peptide library with a conserved coiled-coil dimerization domain (Fos) was constructed in the phagemid vector pCANTAB-5E (Table S1). ${ }^{\mathrm{S} 14}$ The diversity positions were encoded by the NNS mixed codon system, where $\mathrm{N}$ is either $\mathrm{A}, \mathrm{T}, \mathrm{G}$ or $\mathrm{C}$, while $\mathrm{S}$ is $\mathrm{G}$ or $\mathrm{C}$. This codon usage allowed for all 20 amino acids at each position in the library. After transformation into E. coli, the library size was found to be: $1.1 \times 10^{9} \mathrm{CFU}$ (theoretical library size: $1.07 \times 10^{9}$ members).

In our proposed strategy the ability of the Fos coiled-coil domain to effectively dimerize with Jun in the context of phage display is vital to the success of the system. To demonstrate the ability of the Fos leucine zipper domain to dimerize with its partner Jun, we carried out a model competition assay between the phage displayed library and a phage displayed mini-protein $(\mathrm{HTB} 1)^{\mathrm{S} 15}$ against the leucine zipper Jun. The HTB1 mini-protein does not bind to Jun, hence the Fos-containing library should out-compete it in a selection. Jun was synthesized by solid phase peptide synthesis, and a cysteine was attached to its $\mathrm{N}$-terminus via an ethylene glycol derived linker (Novabiochem, product \#01-63-0141). This peptide was immobilized onto a 
maleimide-coated 96-well plate through the cysteine residue. A mixture of the phage particles displaying either the peptide library or the HTB1 mini-protein (1:10) was exposed to the Junimmobilized well or a blank maleimide-coated well. After washing the wells and elution of the phage particles, there was no change in the output composition in the blank well which maintained the 1:10 starting ratio of phage, however, the Jun immobilized well produced a significant (9-fold) enrichment of the Fos tethered peptide library (Figure S4). These results indicate that the Fos dimerization domain is accessible on the surface of the phage particles, thus validating the leucine zipper dimerization portion our approach in this model system.
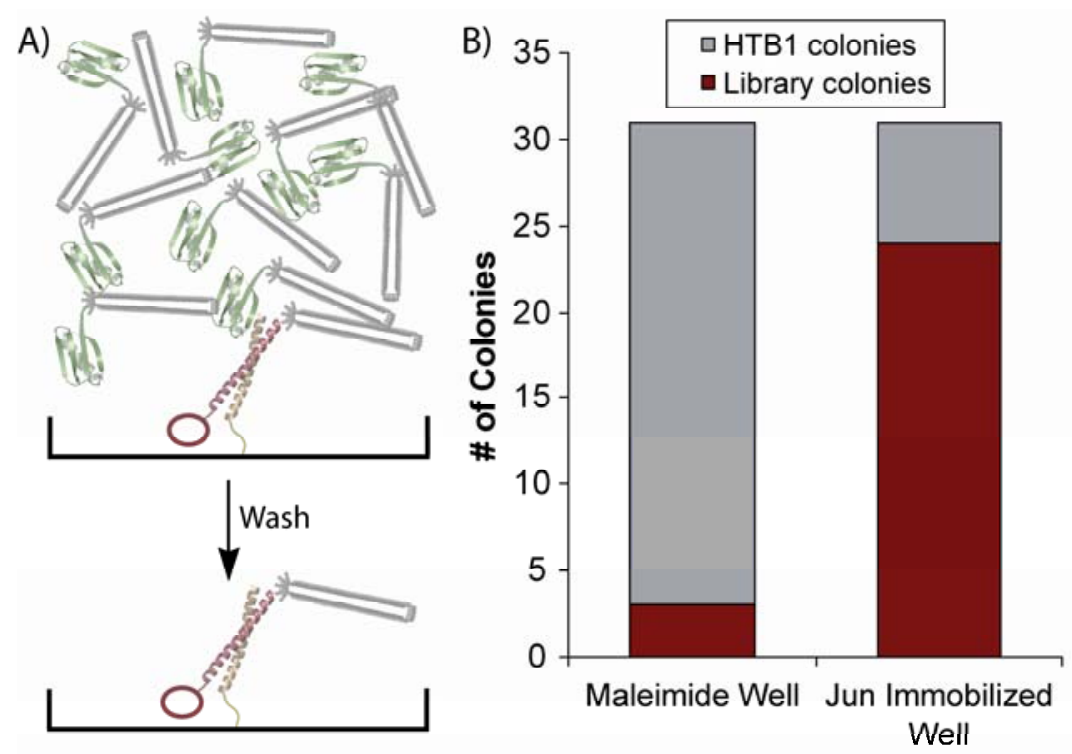

Figure S4: A) Phage display competition between HTB1 and the Fos conjugated cyclic peptide library. B) The results indicate that the library can out-compete the HTB1 mini protein only in the presence of immobilized Jun, thus demonstrating the ability of the leucine zippers to self assemble on the surface of the phage particles. 


\section{Methods}

\section{S3.1. LinkJun synthesis}

For immobilization onto a maleimide functionalized plate, two ethylene glycol based amino acid linker residues (Novabiochem, product \#01-63-0141) followed by a Cys were conjugated to the N-terminus of Jun to form LinkJun (Table S1). Cleavage was carried out with 94\% TFA, 2.5\% EDT, 2.5\% water, and 1\% TIPS for 2 hours. The peptide was precipitated out of solution by the addition of chilled diethyl ether, isolated by centrifugation, and triturated with more chilled ether. HPLC purification (10\% to $50 \%$ acetonitrile gradient in water with $0.1 \%$ TFA) afforded the pure peptide.

\section{S3.2. Phage competition assay}

XL1-Blue E. coli containing the phagemid library vector were grown in the same manner as described in the main manuscript. A sample of E. coli containing a phagemid vector encoding a mini-protein (HTB1), ${ }^{\mathrm{S} 16}$ known not to bind to the leucine zipper Jun, was grown in the same manner. Phage was isolated from both samples of E. coli and the resulting solutions were then quantified by UV absorbance at $268 \mathrm{~nm}^{\mathrm{S} 17}$ and were mixed at a ratio of 10:1 HTB1:Library.

The free cysteine of LinkJun (above) was reacted with a maleimide functionalized Reactibind polystyrene 96-well plate (Pierce) at $100 \mu \mathrm{M}$ for 2 hours. After immobilization, the Jun-containing well was thoroughly rinsed with Tris Buffer A, as was a control well with nothing

immobilized. Both wells were then blocked with $1 \% \beta \mathrm{ME}$ for 1 hour, and again thoroughly washed with Tris Buffer A. One aliquot of the library/HTB1 phage solution was added to each well and allowed to incubate for 2.5 hours. After thorough washing, the bound phage particles were eluted with $10 \mu \mathrm{M}$ Jun for 1 hour. Standard phage elution conditions of glycine $(\mathrm{pH}=2)$ were not appropriate since the Fos/Jun dimer is stable under a wide range of $\mathrm{pH}$ conditions. ${ }^{\mathrm{S} 1}$

The input phage and the phage eluted from both wells were then used to infect three 5 $\mathrm{mL}$ tetracycline-selected cultures of XL1 Blue E. coli $\left(\mathrm{OD}_{600}=0.8\right)$. After 1 hour, $20 \mu \mathrm{L}$ of tenfold serial dilutions of each culture were plated on LB agar plates containing ampicillin and were allowed to grow overnight. Ratios of the library to HTB1 for the samples were determined by PCR screening of the E. coli colonies using the QEF and FosRevW primers. Since FosRev is not complementary to any sequence in the HTB1 gene, only library colonies produced a PCR product with a fragment of DNA at the correct size. DNA from a representative set of colonies 
was sequenced to verify the screening procedure and each sequence corresponded to the identity predicted by the screen.

Primer sequences:

QEF: CGGATAACAATTTCACACAG

FosRev: CGGTGATGGAATTCCCAGCCACCAGCAAGAATAAATTC

\section{S4. Active Site Directed In Vitro Selection Against PKA}

Having demonstrated the feasibility of the model coiled-coil selection system and having shown that both Jun/small-molecule conjugates inhibit PKA, we turned towards the active site directed selection against PKA (Figure S5). Under conditions similar to those of Dalby, et al ${ }^{\mathrm{S} 18}$ we biotinylated the catalytic subunit of PKA followed by immobilization onto NeutrAvidin coated 96-well plates. PKA immobilization was confirmed to be 1 pmol of active enzyme per well by a kinase assay (see section S4.1). As a separate control, we also characterized background binding peptides in our library against NeutrAvidin coated plates ${ }^{\mathrm{S} 14}$ that resulted in a clear consensus of NeutrAvidin binding cyclic peptides. This important control illustrates that it is necessary to consider that our library may also be enriched for NeutrAvidin binders while panning against PKA and thus a pre-incubation step against NeutrAvidin is desirable. Interestingly, the background selections also demonstrated that all of our characterized the NeutrAvidin-binding peptides needed to be cyclic $^{\mathrm{S} 14}$ suggesting that peptide cyclization proceeds efficiently in the context of phage. 


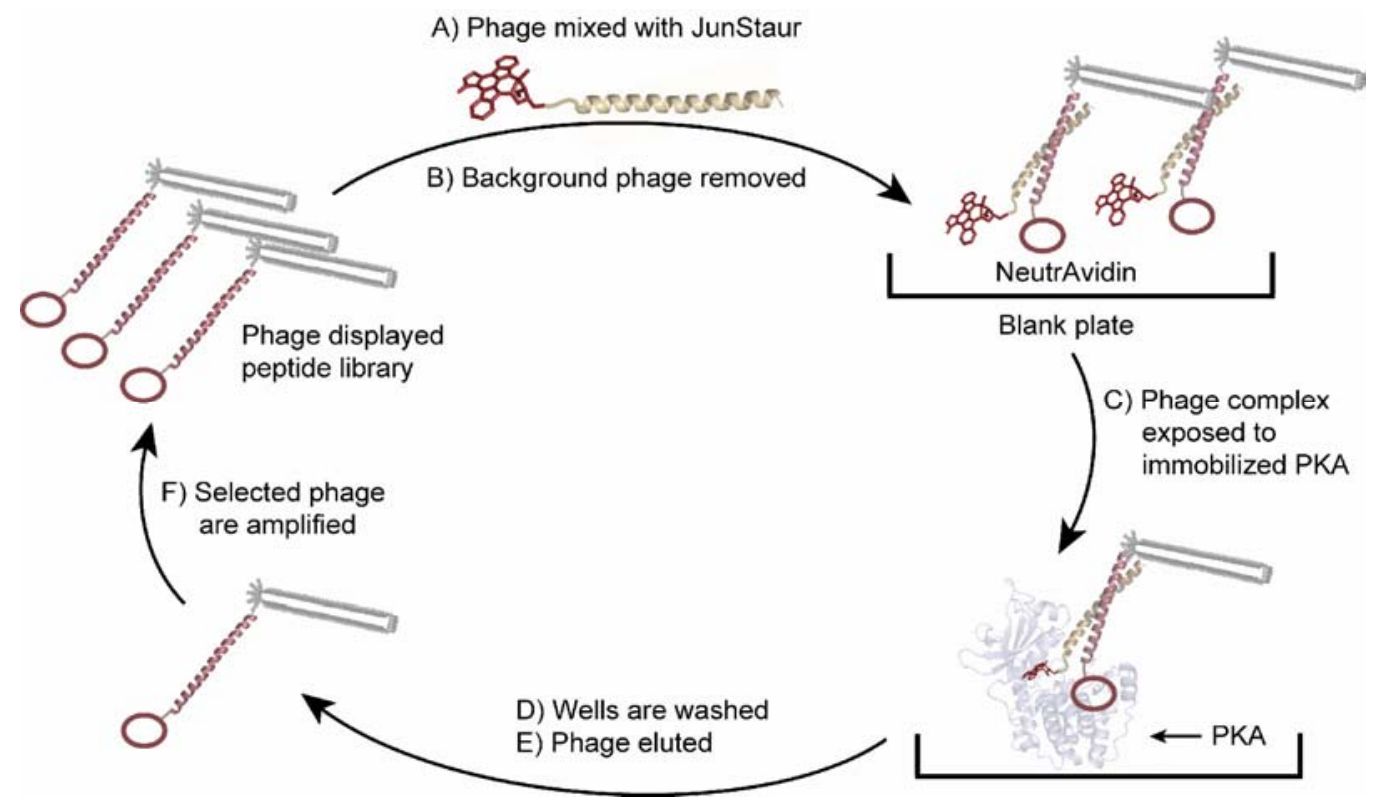

Figure S5: Active site directed selection. The phage displayed cyclic peptide library with the conserved Fos domain is mixed with Jun conjugated to the active site directing small molecule staurosporine. After heterodimerization on the surface of the phage particles, the complex is pre-incubated with a NeutrAvidin-coated well to remove background-binding phage. The unbound phage particles are then transferred to a well containing PKA. After washing to remove weakly bound phage, the tightly bound phage particles are eluted.

With the above reagents and controls in place, we carried out our first selections against PKA utilizing our Fos conjugated library in the presence of $50 \mu \mathrm{M}$ JunAdoC as our active site directing moiety. Despite the pre-incubation with a NeutrAvidin-coated well before every round of selection, the library quickly (4 rounds) converged to the previously reported NeutrAvidinbinding sequences. ${ }^{\mathrm{S} 14}$ These results suggest that a mid to low micromolar PKA targeting ligand is insufficient for isolating Fos-tethered cyclic peptides that bind PKA under our phage display conditions. We next carried out a similar selection with the higher affinity active site directing coiled-coil conjugate, JunStar. As with the selection employing JunAdoC, standard phage display protocols were followed with selections carried out in the presence of $2 \mu \mathrm{M}$ JunStaur. Anticipating tight JunStaur binding to PKA, elution conditions were modified such that bound phage particles were eluted with a low $\mathrm{pH}$ wash in the presence of free staurosporine $(11 \mu \mathrm{M})$ and $10 \%$ DMSO. 
After six rounds of selection, consensus motifs emerged (Table S2). Importantly, we did not observe any of the previously characterized NeutrAvidinbinding peptide sequences as we did with the JunAdoC mediated selection. The most frequently occurring motif was CTFRVFGC, while a second sequence contained a single amino acid change, Leu to Phe, in the fourth position (CTFRVLGC). This possibly indicates that the fourth position in this motif may be variable but possibly hydrophobic. Another potential motif was also observed, though with considerably larger sequence variation. This motif consisted of hydrophobic residues in the first two positions (Met, Val, Leu, or Ile), Pro in the third position, followed by an Arg and Trp in varying configurations in the second
Table S2. Selected phage display results

\begin{tabular}{|c|c|c|}
\hline Name & Peptide & \# Clones ${ }^{\mathrm{a}}$ \\
\hline BS6-3 & CTFRVFGC & 6 \\
\hline BS6-22 & CTFRVLGC & 1 \\
\hline BS6-1 & CMLPRFWC & 4 \\
\hline BS6-45 & CLLPSRWC & 2 \\
\hline BS6-86 & CILPSRWC & 2 \\
\hline BS6-10 & CVESQRVC & 3 \\
\hline BS6-24 & CILPWRHC & 2 \\
\hline BS6-30 & CVLPRWFC & 2 \\
\hline BS6-65 & CILPWSRC & 2 \\
\hline BS6-12 & CIGPRWWC & 2 \\
\hline BS6-63 & CLLPWRAC & 1 \\
\hline BS6-82 & CILPRAWC & 1 \\
\hline BS6-2 & CVLGWRWC & 2 \\
\hline BS6-51 & CVFMRPFC & 2 \\
\hline BS6-52 & CLLRGPWC & 2 \\
\hline BS6-72 & CRWPLILC & 2 \\
\hline BS6-80 & CVRFWPWC & 2 \\
\hline
\end{tabular}

${ }^{\mathrm{a}} 77$ clones were sequenced after the sixth round of selection

half of the peptide. The observed variations in the second motif indicate that these sequences are perhaps too similar in binding affinity to be easily differentiated by phage-display. Interestingly, none of the selected peptides were identical to known physiological substrates of PKA. ${ }^{\mathrm{S} 19}$

\section{Methods}

\section{S4.1. Biotinylation of PKA}

PKA (Promega) was non-selectively biotinylated at surface lysine residues using sulfoNHS-LC-LC-biotin (Pierce). The reaction was carried out in the presence of ATP to block the potential reaction of the active site lysine. ${ }^{\mathrm{S} 18,20} 80 \mu \mathrm{L}$ of the catalytic domain of PKA ( $\left.2 \mathrm{nmol}\right)$ was mixed with $6 \mu \mathrm{L}$ of $1 \mathrm{M} \mathrm{NaOH}$ (to adjust the $\mathrm{pH}$ to $>7.2$ ), $9 \mu \mathrm{L}$ of $10 \mathrm{mM} \mathrm{ATP}$, and $1 \mu \mathrm{L}$ of $10 \mathrm{mM}$ (5 molar equivalents) sulfo-NHS-LC-LC-biotin. After 3 hours at $4{ }^{\circ} \mathrm{C}$, the reaction was quenched by the addition of $15 \mathrm{~mL}$ of Tris Buffer A $(20 \mathrm{mM}$ Tris- $\mathrm{HCl}, 150 \mathrm{mM} \mathrm{NaCl}$, and $0.05 \%$ Tween 20 at $\mathrm{pH}=7.4$ ). The enzyme was then concentrated in a $5000 \mathrm{MWCO}$ centrifuge concentrator, and rediluted in Tris Buffer A. This process was repeated until the theoretical concentration of the biotinylation reagent was $<100 \mathrm{nM}$ and the PKA concentration was $1 \mu \mathrm{M}$. A kinase assay was run to determine the extent of PKA immobilization. Upon immobilization 
onto a NeutrAvidin coated 96-well plate, the equivalent of 1 pmol of active kinase was detected per well.

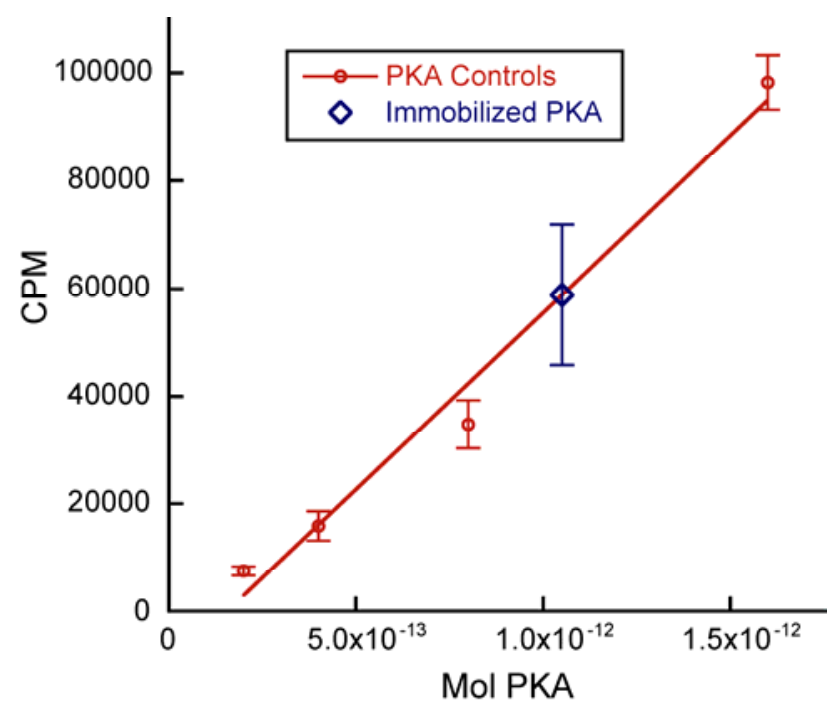

Figure S6: Quantification of biotinylated PKA immobilized on NeutrAvidin coated plates. Control PKA and immobilized PKA reactions and were run in duplicate. Error bars indicate standard deviation.

\section{S4.2. Active site directed phage displayed peptide selection against PKA.}

The phage display cyclic peptide library conjugated to Fos was constructed in the phagemid vector pCANTAB-5E and the phage particles were isolated as described previously S14. Biotinylated PKA (from above, $100 \mu \mathrm{L}, 500 \mathrm{nM}$ ) was placed in one well of a NeutrAvidin coated 96-well plate (Pierce) on ice. After 1 hour, the excess PKA was removed and the well was washed thoroughly with Tris Buffer A.

For the JunAdoC selection, the phage solution was mixed with JunAdoC (50 $\mu \mathrm{M}$ final) and stored on ice for 30 minutes. The JunAdoC/phage solution was exposed to a pre-washed blank NeutrAvidin well for $1 \mathrm{hr}$ to remove NeutrAvidin-binding phage. After this preincubation, the phage solution was transferred to the well containing the immobilized PKA, and allowed to equilibrate for $2 \mathrm{hr}$. The weakly bound phage were washed away with Tris Buffer A (containing $25 \mu \mathrm{M}$ JunAdoC) six times for 2 minutes each. After washing, the phage were eluted by adding $0.2 \mathrm{M}$ glycine $(\mathrm{pH}=2.0)$ for 10 minutes. The elution mixture was then transferred to a tube containing $2 \mathrm{M}$ Tris base $(\mathrm{pH}=11)$ to neutralize the solution.

In the JunStaur selection, the phage solution was mixed with JunStaur $(2 \mu \mathrm{M}$ final concentration) and was stored on ice for 30 minutes. The JunStaur/phage solution was pre- 
incubated in a NeutrAvidin well for 30 minutes and then transferred to the well containing immobilized PKA for an additional 30 minutes. The weakly bound phage particles were washed with Tris Buffer A in increasing time intervals during subsequent rounds of selection. During the first round of selection, the well was washed 5 X 1 minute per wash. With each subsequent round of selection, the soaking time was increased by 2 minutes. After washing, the phage were eluted by adding $100 \mu \mathrm{L}$ of $0.2 \mathrm{M}$ glycine $(\mathrm{pH}=2.0)$ with $11 \mu \mathrm{M}$ staurosporine in a $10 \%$ DMSO aqueous solution. After a 10 minute equilibration, the elution solution was transferred to a tube with $40 \mu \mathrm{L}$ of $2 \mathrm{M}$ Tris base $(\mathrm{pH}=11)$. Treating control phage with these conditions showed no significant loss in viability. Phage were recovered and the library was propagated as previously described. ${ }^{\text {S14 }}$

\section{S5. Evaluation of Selected Cyclic Peptides}

Since no single variant of the second motif dominated the output, we chose a representative example, BS6-45, along with more frequently isolated sequences for our characterization efforts. Hence, the selected peptides BS6-3, BS6-1, BS6-45, and BS6-10 were synthesized and subsequently cyclized by the formation of intramolecular disulfide bonds to provide cyclo(CTFRVFGC)G (identified as 3 in the main manuscript), cyclo(CMLPRFWC)G, cyclo(CLLPSRWC)G, and cyclo(CVESQRVC)G, respectively. The peptides were assayed for their ability to inhibit PKA mediated phosphorylation. Except for BS6-10, the peptides all showed activity in the mid micromolar range (Figure S7): $\mathrm{IC}_{50}$ for BS6-3 was $79 \pm 2 \mu \mathrm{M}$, BS6-1 was $99 \pm 3 \mu \mathrm{M}$, and BS6-45 was $310 \pm 19 \mu \mathrm{M}$. An accurate $\mathrm{IC}_{50}$ value for BS6-10 could not be determined, though it was $>1 \mathrm{mM}$. The success of the first three peptides in inhibiting PKA indicates that this new ligand guided selection strategy was able to enrich the library for peptides that bind to PKA. Comparing the JunAdoC $\left(\mathrm{IC}_{50}=21 \pm 2 \mu \mathrm{M}\right)$ and JunStaur $\left(\mathrm{IC}_{50}=78 \pm 11 \mathrm{nM}\right)$ directed selections suggests that high affinity active site directing ligands are necessary to out-

compete background binding motifs, ${ }^{\mathrm{S} 14}$ even when a negative selection step is incorporated. It is also likely that tuning the coiled-coil affinity may similarly impact our fragment based selection approach. 


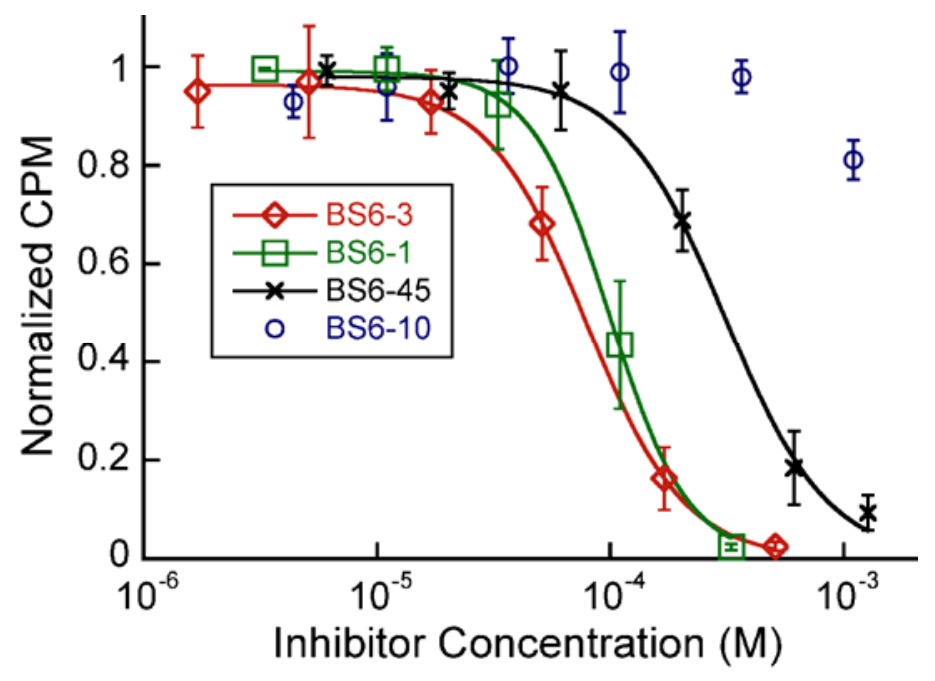

Figure S7: Inhibition of PKA with selected peptides. Synthesized cyclic peptides BS6-3 (3), BS6-1, BS6-45, and BS6-10 were interrogated for their ability to inhibit PKA. The lines represent the best fit for the $\mathrm{IC}_{50}$ calculation (equation S1) and the error bars indicate standard deviation. An accurate $\mathrm{IC}_{50}$ value for BS6-10 could not be determined.

\section{Methods}

\section{S5.1. Synthesis of Selected Cyclic Peptides}

The variable regions of the selected peptides $\left(\mathrm{C}(\mathrm{X})_{6} \mathrm{CG}\right)$ were synthesized, cleaved from the resin, and initially purified in the same manner as Jun described above. After purification by HPLC, the peptides were cyclized by the oxidation of the two conserved Cys residues to form intramolecular disulfide bonds. To achieve this, each peptide was dissolved in phosphate buffered saline (PBS, $\mathrm{pH}=7.4$ ) with $20 \%$ DMSO and allowed to shake for 48 hours at $37^{\circ} \mathrm{C}$. The extent of cyclization was monitored with Ellman's reagent. ${ }^{\mathrm{S} 14}$ The cyclized peptides were characterized by MALDI mass spectrometry and amino acid analysis (W.M. Keck Facility, Yale University).

Table S3: Mass spectrometry results for synthesized cyclic peptides

\begin{tabular}{llll}
\hline Name & Sequence & Expected Mass $(\mathrm{g} / \mathrm{mol})$ & Found $(\mathrm{m} / \mathrm{z})$ \\
\hline BS6-1 & cyclo(CMLPRFWC)G & 1109.3 & 1109.4 \\
BS6-3 (3) & cyclo(CTFRVFGC)G & 986.1 & 986.4 \\
BS6-10 & cyclo(CVESQRVC)G & 977.1 & 977.5 \\
BS6-45 & cyclo(CLLPSRWC)G & 1031.2 & 1031.4
\end{tabular}


Table S4: Amino acid analysis results for synthesized cyclic peptides

\begin{tabular}{|c|c|c|c|c|c|c|c|c|c|c|c|}
\hline & Glx & Phe & Gly & Leu & Met & Pro & Arg & Ser & Thr & Val & Trp \\
\hline BS6-1 & & $1.07(1)$ & $1.13(1)$ & $1.06(1)$ & $0.70(1)$ & $1.01(1)$ & $1.03(1)$ & & & & $\operatorname{nd}(1)$ \\
\hline BS6-3 (3) & & $2.1(2)$ & $2.0(2)$ & & & & $0.97(1)$ & & $0.92(1)$ & $0.97(1)$ & \\
\hline BS6-10 & $2.12(2)$ & & $1.06(1)$ & & & & $0.97(1)$ & $0.73(1)$ & & $2.12(2)$ & \\
\hline BS6-45 & & & $1.12(1)$ & $2.08(2)$ & & $1.00(1)$ & $1.01(1)$ & $0.78(1)$ & & & $\mathrm{nd}(1)$ \\
\hline
\end{tabular}

\section{S5.2. PKA Inhibition Assay}

The ability of Jun conjugates and the selected cyclic peptides to inhibit PKA was interrogated via a kinase assay utilizing $\left[\gamma^{32} \mathrm{P}\right]$ ATP $(30 \mu \mathrm{M})$ as the phosphate source and Kemptide as the peptide substrate (LRRASLG, $30 \mu \mathrm{M})$. The assays $(30 \mu \mathrm{L})$ were carried out at room temperature $\left(25 \pm 1{ }^{\circ} \mathrm{C}\right)$ for 6 minutes in $40 \mathrm{mM}$ Tris- $\mathrm{HCl}, 20 \mathrm{mM}$ magnesium acetate $(\mathrm{pH}$ $=7.4$ ), and $0.01 \%$ BSA with an enzyme concentration of $26 \mathrm{nM}$. Cyclic peptide assays were run in the presence of $2.5 \%$ DMSO. Each assay mixture was quenched with $20 \mu \mathrm{L}$ of $0.85 \%$ phosphoric acid and $30 \mu \mathrm{L}$ was spotted on P81 phosphocellulose paper (Upstate). The samples were then washed $3 \times 500 \mathrm{~mL}$ of $0.85 \%$ phosphoric acid and $1 \times 500 \mathrm{~mL}$ ethanol for 5 minutes each. The amount of ${ }^{32} \mathrm{P}$ labeling of the peptide substrate was quantified using a Beckman LS 6000IC liquid scintillation counter. Data were normalized to reactions containing no inhibitors, which were run in triplicate. The inhibition data were compiled as an average of at least two separate experiments and fit to the following equation:

$$
y=\frac{C_{\max }}{1+\left(\frac{x}{I C_{50}}\right)^{n}}
$$

where $y$ is the normalized counts per minute of radioactive decay, $x$ is the concentration of the inhibitor, $C_{\max }$ is the maximum observed signal, and $n$ is the slope. Best fit equations were calculated using KaleidaGraph (Synergy Software).

\section{S5.3. Synthesis of cyclo(CTFRVFGC)G Staurosporine Conjugate, 4}

The peptide CTFRVFGCG (3) was synthesized with standard Fmoc protection strategies for solid phase peptide synthesis (see section 5.1). After completion of the peptide sequence, a ethylene glycol derived linker (Novabiochem, product \#01-63-0141) was attached to the Nterminus using identical reaction conditions. The carboxylated staurosporine derivative 2 was 
attached to the linker under slightly modified conditions: 1.5 equivalents of the carboxylated staurosporine derivative, 2 equivalents of pyBOP, and 4 equivalents of DIEA. The reaction was allowed to proceed until the kaiser test of a small portion of the resin produced negative results ( 2 hours). Cleavage and initial purification was carried out as above. After cleavage, the peptide was protected from light exposure due to the sensitivity of staurosporine to light. HPLC purification ( $40 \%$ to $65 \%$ acetonitrile gradient in water with $0.1 \%$ TFA) afforded the pure linear staurosporine peptide hybrid.

Cyclization of the peptide was achieved through the oxidation of the two Cys residues to form an intramolecular disulfide bond. The linear peptide staurosporine conjugate was dissolved in phosphate buffered saline (PBS, $\mathrm{pH}=7.4$ ) with $10 \%$ DMSO and allowed to shake for 48 hours at $37^{\circ} \mathrm{C}$. After cyclization, the peptide staurosporine conjugate was resubjected to HPLC purification under the same conditions as above. The resulting product was characterized by MALDI mass spectrometry (expected: $1853 \mathrm{~g} / \mathrm{mol}$ found: $1853.2 \mathrm{~m} / \mathrm{z}$ ) and amino acid analysis (Thr (1) 0.95; Gly (2) 2.2; Val (1) 0.89). Due to interference in the HPLC trace caused by the staurosporine derivative and linker, Phe and Arg were not able to be accurately quantified.

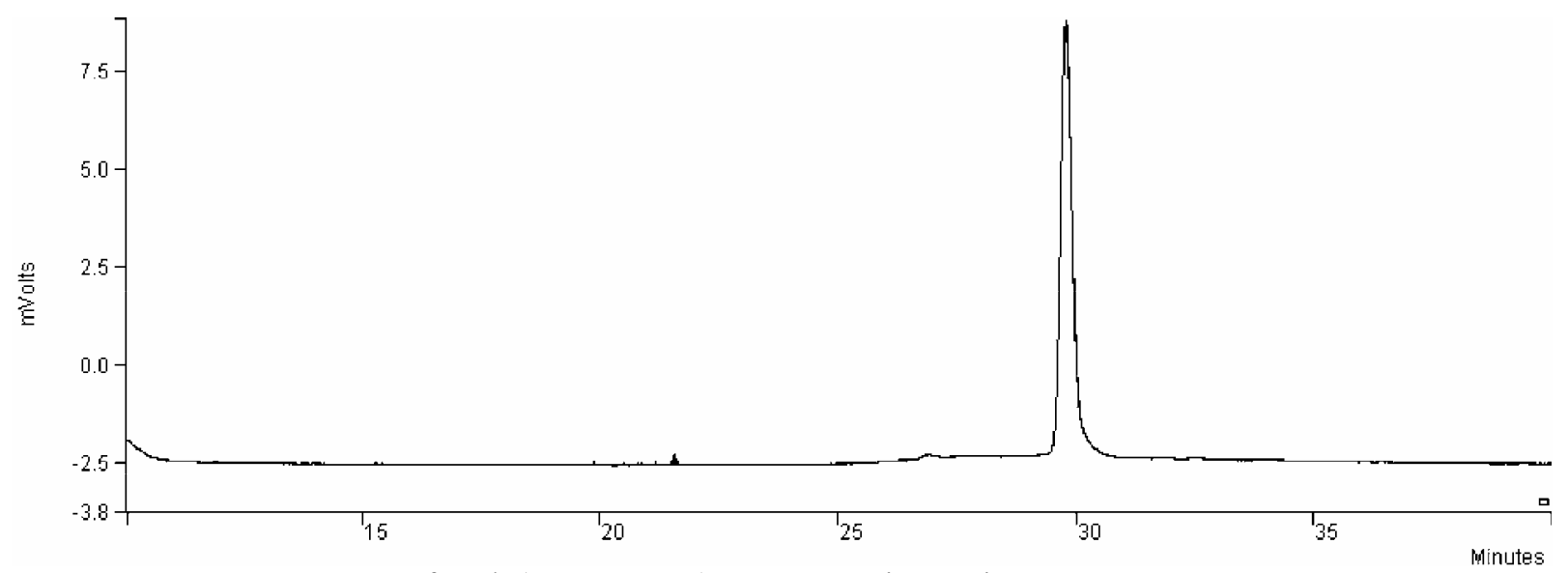

Figure S8: HPLC trace of cyclo(CTFRVFGC)G staurosporine conjugate 4.

S5.4. PKA Inhibition by the Carboxylated Staurosporine Derivative 2, Cyclic Peptide 3, and Bivalent Inhibitor 4

The $\mathrm{IC}_{50}$ values of the cyclic peptide 3 (cyclo(CTFRVFGC)G) or carboxylated staurosporine 2 alone and conjugated through a ethylene glycol linker 4 were determined for PKA. Due to the tight-binding nature of the bivalent inhibitor $\mathbf{4}$, the concentration of enzyme in 
the PKA assay was reduced. ${ }^{\text {S21 }}$ The enzymatic phosphorylation reactions were run as above (section S5.2), though with $2.6 \mathrm{nM}$ of PKA (a 10-fold reduction in enzyme concentration). Data were normalized to reactions containing no inhibitor; reported data is the average of three separate experiments (Figure 2B, main manuscript). The averaged data was fit to the same equation as above. The concentrations of inhibitors containing peptide components were determined by amino acid analysis, while the concentration of carboxylated staurosporine was determined spectroscopically $\left(\varepsilon_{292}=57.4 \mathrm{mM}^{-1} \mathrm{~cm}^{-1}\right)$.

\section{S5.5. Millipore Kinase Profiler Screen}

The Kinase Profiler service offered by Millipore (formerly Upstate) has been utilized recently to determine the selectivity of inhibitors over a range of protein kinases. ${ }^{\text {S22 }}$ The kinases we chose for the interrogation of the selectivity of our inhibitors were: ASK1 (Official Symbol: MAP3K5, GenBank Accession \#NM 005923); CaMKIIß (Official Symbol: CAMK2B,

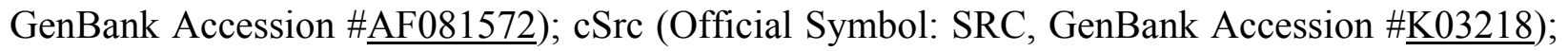
EphA5 (Official Symbol: EPHA5, GenBank Accession \#NM_004439); Mnk2 (Official Symbol: MKNK2, GenBank Accession \#NM 017572); PKA (Official Symbol: PRKACA, GenBank Accession \# $\underline{X 07767}$ ). The concentrations of inhibitors were determined as above, and the following protocols were used by Millipore (http://www.upstate.com/features/kp protocols.asp), according to company literature:

ASK1 (h): In a final reaction volume of $25 \mu \mathrm{L}$, ASK1 (h) $(5-10 \mathrm{mU})$ is incubated with $8 \mathrm{mM}$ MOPS pH 7.0, 0.2 mM EDTA, $0.33 \mathrm{mg} / \mathrm{mL}$ myelin basic protein, $10 \mathrm{mM} \mathrm{MgAcetate}$ and $\left[\gamma_{-}{ }^{33} \mathrm{P}-\right.$ ATP] (specific activity approx. $500 \mathrm{cpm} / \mathrm{pmol}$, concentration as required). The reaction is initiated by the addition of the $\mathrm{MgATP}$ mix. After incubation for 40 minutes at room temperature, the reaction is stopped by the addition of $5 \mu \mathrm{L}$ of a $3 \%$ phosphoric acid solution. 10 $\mu \mathrm{L}$ of the reaction is then spotted onto a P30 filtermat and washed three times for 5 minutes in 75 $\mathrm{mM}$ phosphoric acid and once in methanol prior to drying and scintillation counting.

CaMKII (h): In a final reaction volume of $25 \mu \mathrm{L}$, CaMKII $\beta$ (h) (5-10 mU) is incubated with 8 mM MOPS pH 7.0, $0.2 \mathrm{mM}$ EDTA, $0.5 \mathrm{mM} \mathrm{CaCl2,} 16 \mu \mathrm{g} / \mathrm{mL}$ calmodulin, $250 \mu \mathrm{M}$ KKLNRTLSFAEPG, $10 \mathrm{mM}$ MgAcetate and $\left[\gamma-{ }^{33} \mathrm{P}-\mathrm{ATP}\right]$ (specific activity approx. 500 
$\mathrm{cpm} / \mathrm{pmol}$, concentration as required). The reaction is initiated by the addition of the MgATP mix. After incubation for 40 minutes at room temperature, the reaction is stopped by the addition of $5 \mu \mathrm{L}$ of a $3 \%$ phosphoric acid solution. $10 \mu \mathrm{L}$ of the reaction is then spotted onto a P30 filtermat and washed three times for 5 minutes in $75 \mathrm{mM}$ phosphoric acid and once in methanol prior to drying and scintillation counting.

cSRC (h): In a final reaction volume of $25 \mu \mathrm{L}$, c-SRC (h) $(5-10 \mathrm{mU})$ is incubated with $8 \mathrm{mM}$ MOPS pH 7.0, $0.2 \mathrm{mM}$ EDTA, $250 \mu \mathrm{M}$ KVEKIGEGTYGVVYK (Cdc2 peptide), $10 \mathrm{mM}$ MgAcetate and $\left[\gamma^{33} \mathrm{P}-\mathrm{ATP}\right]$ (specific activity approx. $500 \mathrm{cpm} / \mathrm{pmol}$, concentration as required). The reaction is initiated by the addition of the MgATP mix. After incubation for 40 minutes at room temperature, the reaction is stopped by the addition of $5 \mu \mathrm{L}$ of a $3 \%$ phosphoric acid solution. $10 \mu \mathrm{L}$ of the reaction is then spotted onto a P30 filtermat and washed three times for 5 minutes in $75 \mathrm{mM}$ phosphoric acid and once in methanol prior to drying and scintillation counting.

EphA5 (h): In a final reaction volume of $25 \mu \mathrm{L}$, EphA5 (h) $(5-10 \mathrm{mU})$ is incubated with $8 \mathrm{mM}$ MOPS pH 7.0, $0.2 \mathrm{mM}$ EDTA, $2.5 \mathrm{mM} \mathrm{MnCl2,} 0.1 \mathrm{mg} / \mathrm{mL}$ poly (Glu, Tyr) 4:1, $10 \mathrm{mM}$ $\mathrm{MgAcetate}$ and $\left[\gamma_{-}{ }^{33} \mathrm{P}-\mathrm{ATP}\right]$ (specific activity approx. $500 \mathrm{cpm} / \mathrm{pmol}$, concentration as required). The reaction is initiated by the addition of the MgATP mix. After incubation for 40 minutes at room temperature, the reaction is stopped by the addition of $5 \mu \mathrm{L}$ of a $3 \%$ phosphoric acid solution. $10 \mu \mathrm{L}$ of the reaction is then spotted onto a Filtermat $\mathrm{A}$ and washed three times for 5 minutes in $75 \mathrm{mM}$ phosphoric acid and once in methanol prior to drying and scintillation counting.

Mnk2 (h): In a final reaction volume of $25 \mu \mathrm{L}, \operatorname{Mnk} 2(\mathrm{~h})(5-10 \mathrm{mU})$ is incubated with $8 \mathrm{mM}$ MOPS pH 7.0, $0.2 \mathrm{mM}$ EDTA, $0.33 \mathrm{mg} / \mathrm{mL}$ myelin basic protein, $10 \mathrm{mM} \mathrm{MgAcetate}$ and $\left[\gamma_{-}{ }^{33} \mathrm{P}-\right.$ ATP] (specific activity approx. $500 \mathrm{cpm} / \mathrm{pmol}$, concentration as required). The reaction is initiated by the addition of the MgATP mix. After incubation for 40 minutes at room temperature, the reaction is stopped by the addition of $5 \mu \mathrm{L}$ of a $3 \%$ phosphoric acid solution. 10 $\mu \mathrm{L}$ of the reaction is then spotted onto a P30 filtermat and washed three times for 5 minutes in 75 $\mathrm{mM}$ phosphoric acid and once in methanol prior to drying and scintillation counting. 
PKA (h): In a final reaction volume of $25 \mu \mathrm{L}$, PKA (h) (5- $10 \mathrm{mU})$ is incubated with $8 \mathrm{mM}$ MOPS pH 7.0, $0.2 \mathrm{mM}$ EDTA, $30 \mu \mathrm{M}$ LRRASLG (Kemptide), $10 \mathrm{mM} \mathrm{MgAcetate}$ and $\left[\gamma_{-}{ }^{33} \mathrm{P}-\right.$ ATP] (specific activity approx. $500 \mathrm{cpm} / \mathrm{pmol}$, concentration as required). The reaction is initiated by the addition of the MgATP mix. After incubation for 40 minutes at room temperature, the reaction is stopped by the addition of $5 \mu \mathrm{L}$ of a $3 \%$ phosphoric acid solution. 10 $\mu \mathrm{L}$ of the reaction is then spotted onto a P30 filtermat and washed three times for 5 minutes in 50 $\mathrm{mM}$ phosphoric acid and once in methanol prior to drying and scintillation counting. 


\section{S6. Structural Alignments of Kinases}

The structure of PKA aligned with sequences of (a) ASK1 (Official Symbol: MAP3K5); (b) CaMKII $\beta$ (Official Symbol: CAMK2B); (c) cSrc (Official Symbol: SRC); (d) EphA5 (Official Symbol: EPHA5); and (e) Mnk2 (Official Symbol: MKNK2).

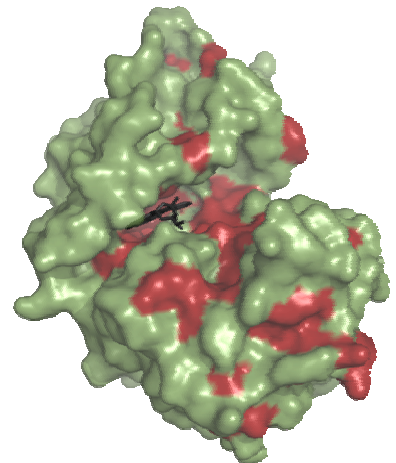

PKA vs. Ask1 $32 \%$ Identity $50 \%$ Similarity

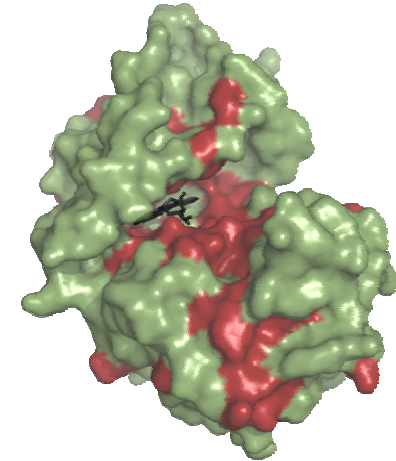

PKA vs. CaMKIIb $29 \%$ Identity $50 \%$ Similarity

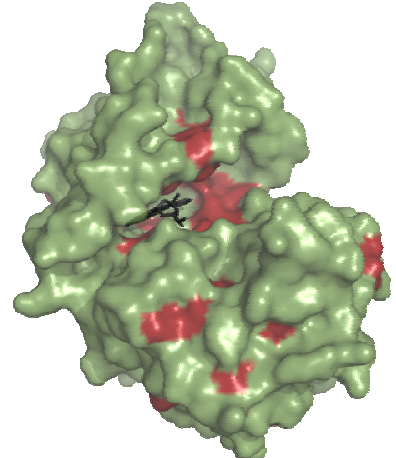

PKA vs. cSrc $24 \%$ Identity 45\% Similarity

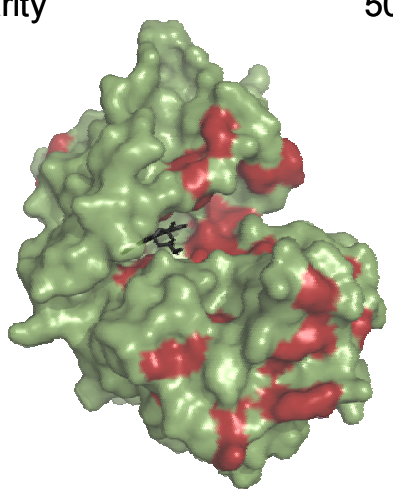

PKA vs. EphA5 $25 \%$ Identity 45\% Similarity

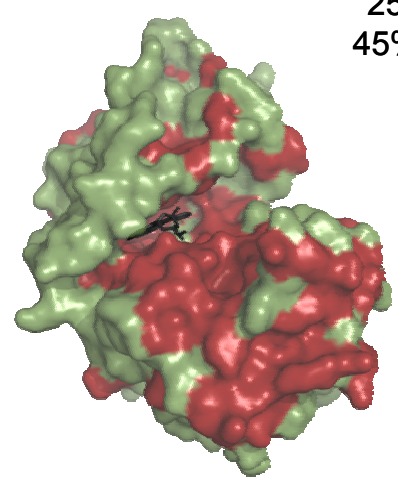

All similarity overlaid

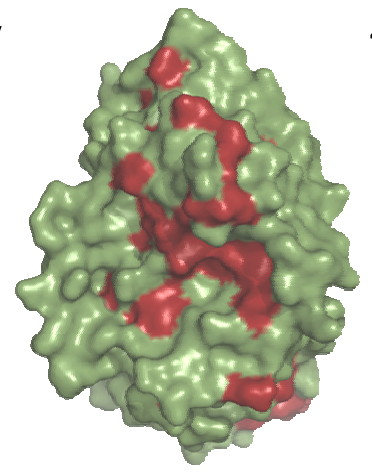

$120^{\circ}$ rotation around the $y$ axis

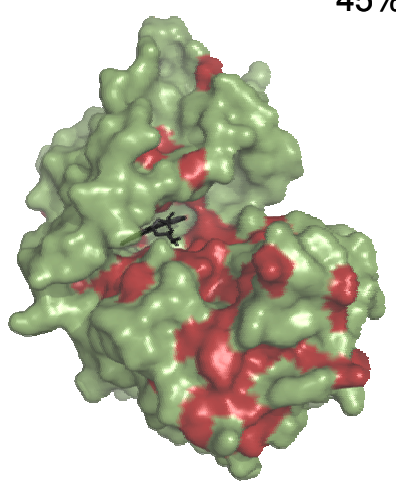

PKA vs. Mnk2

$26 \%$ Identity $44 \%$ Similarity

Figure S9: Sequence alignments (bl2seq) ${ }^{\text {S23 }}$ of PKA with the kinases from the selectivity screen mapped onto the structure of PKA bound to staurosporine ${ }^{\mathrm{S} 11}$ (PDB ID: 1STC). Identical residues between kinases are represented in red; other residues are green; and staurosporine is seen in the ATP binding pocket (black sticks). Models were rendered using Pymol; DeLano, W.L. (http://www.pymol.org). 


\section{References}

S1. Oshea, E. K.; Rutkowski, R.; Kim, P. S., Mechanism of specificity in the Fos-Jun oncoprotein heterodimer. Cell 1992, 68, (4), 699-708.

S2. Zhou, M.; Ghosh, I., Noncovalent multivalent assembly of jun peptides on a leucine zipper dendrimer displaying fos peptides. Org. Lett. 2004, 6, (20), 3561-4.

S3. Daugherty, D. L.; Gellman, S. H., A fluorescence assay for leucine zipper dimerization: Avoiding unintended consequences of fluorophore attachment. J. Am. Chem. Soc. 1999, 121, (18), 4325-4333.

S4. Kohler, J. J.; Schepartz, A., Kinetic studies of Fos.Jun.DNA complex formation: DNA binding prior to dimerization. Biochemistry 2001, 40, (1), 130-42.

S5. Corbett, P. T.; Leclaire, J.; Vial, L.; West, K. R.; Wietor, J. L.; Sanders, J. K. M.; Otto, S., Dynamic combinatorial chemistry. Chem. Rev. 2006, 106, (9), 3652-3711.

S6. Loog, M.; Uri, A.; Raidaru, G.; Jarv, J.; Ek, P., Adenosine-5'-carboxylic acid peptidyl derivatives as inhibitors of protein kinases. Bioorg. Med. Chem. Lett. 1999, 9, (10), 1447-52.

S7. Maly, D. J.; Choong, I. C.; Ellman, J. A., Combinatorial target-guided ligand assembly: Identification of potent subtype-selective c-Src inhibitors. Proc. Natl. Acad. Sci. U.S.A. 2000, 97, (6), 2419-2424.

S8. Fabian, M. A.; Biggs, W. H., 3rd; Treiber, D. K.; Atteridge, C. E.; Azimioara, M. D.; Benedetti, M. G.; Carter, T. A.; Ciceri, P.; Edeen, P. T.; Floyd, M.; Ford, J. M.; Galvin, M.; Gerlach, J. L.; Grotzfeld, R. M.; Herrgard, S.; Insko, D. E.; Insko, M. A.; Lai, A. G.; Lelias, J. M.; Mehta, S. A.; Milanov, Z. V.; Velasco, A. M.; Wodicka, L. M.; Patel, H. K.; Zarrinkar, P. P.; Lockhart, D. J., A small molecule-kinase interaction map for clinical kinase inhibitors. Nat. Biotechnol. 2005, 23, (3), 329-36.

S9. Caravatti, G.; Meyer, T.; Fredenhagen, A.; Trinks, U.; Mett, H.; Fabbro, D., Inhibitory activity and selectivity of staurosporine derivatives towards protein kinase C. Bioorg. Med. Chem. Lett. 1994, 4, (3), 399-404.

S10. Toledo, L. M.; Lydon, N. B., Structures of staurosporine bound to CDK2 and cAPK--new tools for structure-based design of protein kinase inhibitors. Structure 1997, 5, (12), 1551-6.

S11. Prade, L.; Engh, R. A.; Girod, A.; Kinzel, V.; Huber, R.; Bossemeyer, D., Staurosporineinduced conformational changes of cAMP-dependent protein kinase catalytic subunit explain inhibitory potential. Structure 1997, 5, (12), 1627-37.

S12. Schneider, T. L.; Mathew, R. S.; Rice, K. P.; Tamaki, K.; Wood, J. L.; Schepartz, A., Increasing the kinase specificity of K252a by protein surface recognition. Org. Lett. 2005, 7, (9), 1695-8.

S13. Epp, J. B.; Widlanski, T. S., Facile preparation of nucleoside-5 '-carboxylic acids. J. Org. Chem. 1999, 64, (1), 293-295.

S14. Meyer, S. C.; Gaj, T.; Ghosh, I., Highly selective cyclic peptide ligands for NeutrAvidin and avidin identified by phage display. Chem. Biol. Drug. Des. 2006, 68, (1), 3-10.

S15. Malakauskas, S. M.; Mayo, S. L., Design, structure and stability of a hyperthermophilic protein variant. Nat. Struct. Biol. 1998, 5, (6), 470-5.

S16. Meyer, S. C.; Huerta, C.; Ghosh, I., Single-site mutations in a hyperthermophilic variant of the B1 domain of protein G result in self-assembled oligomers. Biochemistry 2005, 44, (7), 2360-8.

S17. Burton, D. R.; Scott, J. K.; Silverman, G. J.; Barbas, C. F., Phage display: a laboratory manual. Cold Spring Harbor Laboratory Press: Cold Spring Harbor, NY, 2001. 
S18. Rainey, M. A.; Linse, K. D.; Dalby, K. N., Phage display identifies novel peptides that bind extracellular-regulated protein kinase 2 to compete with transcription factor binding. $J$. Phys. Org. Chem. 2004, 17, (6-7), 461-471.

S19. Shabb, J. B., Physiological substrates of cAMP-dependent protein kinase. Chem. Rev. 2001, 101, (8), 2381-411.

S20. Zheng, J. H.; Knighton, D. R.; Teneyck, L. F.; Karlsson, R.; Xuong, N. H.; Taylor, S. S.; Sowadski, J. M., Crystal structure of the catalytic subunit of cAMP-dependent protein kinase complexed with MgATP and peptide inhibitor. Biochemistry 1993, 32, (9), 2154-2161.

S21. Wu, Q.; Criscione, K. R.; Grunewald, G. L.; McLeish, M. J., Phenylethanolamine Nmethyltransferase inhibition: re-evaluation of kinetic data. Bioorg Med Chem Lett 2004, 14, (16), 4217-20.

S22. Enkvist, E.; Lavogina, D.; Raidaru, G.; Vaasa, A.; Viil, I.; Lust, M.; Viht, K.; Uri, A., Conjugation of adenosine and hexa-(D-arginine) leads to a nanomolar bisubstrate-analog inhibitor of basophilic protein kinases. J. Med. Chem. 2006, 49, (24), 7150-9.

S23. Tatusova, T. A.; Madden, T. L., BLAST 2 Sequences, a new tool for comparing protein and nucleotide sequences. FEMS Microbiol. Lett. 1999, 174, (2), 247-50.

\section{Complete references $1 \mathrm{a}$ and $5 \mathrm{~b}$ from main manuscript.}

(1) (a) Szczepankiewicz, B. G.; Liu, G.; Hajduk, P. J.; Abad-Zapatero, C.; Pei, Z.; Xin, Z.; Lubben, T. H.; Trevillyan, J. M.; Stashko, M. A.; Ballaron, S. J.; Liang, H.; Huang, F.; Hutchins, C. W.; Fesik, S. W.; Jirousek, M. R. J. Am. Chem. Soc. 2003, 125, (14), 40874096.

(4) (b) Fabian, M. A.; Biggs, W. H., 3rd; Treiber, D. K.; Atteridge, C. E.; Azimioara, M. D.; Benedetti, M. G.; Carter, T. A.; Ciceri, P.; Edeen, P. T.; Floyd, M.; Ford, J. M.; Galvin, M.; Gerlach, J. L.; Grotzfeld, R. M.; Herrgard, S.; Insko, D. E.; Insko, M. A.; Lai, A. G.; Lelias, J. M.; Mehta, S. A.; Milanov, Z. V.; Velasco, A. M.; Wodicka, L. M.; Patel, H. K.; Zarrinkar, P. P.; Lockhart, D. J. Nat Biotechnol 2005, 23, (3), 329-336. 